\title{
MICROCHIP HUMANO E A SOCIEDADE DA INFORMAÇÃO: UM MUNDO NOVO A SER ANALISADO EM FACE DOS 30 ANOS DA CONSTITUIÇÃO FEDERAL BRASILEIRA
}

\author{
HUMAN MICROCHIP AND THE INFORMATION SOCIETY: A NEW WORLD TO BE \\ ANALYZED IN FACE OF THE 30 YEARS OF THE BRAZILIAN FEDERAL CONSTITUTION
}

\section{Greice Patricia Fuller}

Pós-Doutora em Direito na Universidad de Navarra /Espanha com bolsa da CAPES. Doutora e Mestre em Direito das Relações Sociais pela PUC/SP.

Especialista em Direito Espanhol para Juristas estrangeiros pela Universidad de Alcalá - Madrid. Professora das Faculdades de Direito e Economia e

Pós-Graduação Lato Sensu de Direitos Difusos e Coletivos PUC/SP. Professora da Faculdade de Direito do Programa de Mestrado em Direito da Sociedade da Informação da FMU. E-mail: greicepf@uol.com.br

\section{Danielle de Mello Basso}

Mestranda em Direito da Sociedade da Informação pelo Programa de Mestrado em Direito da Sociedade da Informação do Centro Universitário das Faculdades Metropolitanas Unidas - FMU de São Paulo. Especialista em

Direito das Relações do Trabalho pela Faculdade de Direito de São Bernardo do Campo - FDSBC. Advogada E-mail:danielle.mbasso@gmail.com

Recebido em: 11/09/2018

Aprovado em: 16/02/2019

RESUMO: O artigo analisa tema atual em face dos 30 anos da Constituição Federal brasileira, qual seja, o microchip humano, abordando aspectos técnicos, como suas características e forma de implantação, bem como os reflexos de sua utilização para o mundo jurídico.O trabalho apresenta a preocupação quanto à homeostase do ontos constitucional pátrio quando do uso do microchip humano em face de dados pessoais nele guardados, apontando a possibilidade que seu uso gera de violações aos direitos à intimidade, privacidade, honra e imagem, caso os mesmos sejam comercializados ou disponibilizados sem a devida autorização do seu proprietário, demonstrando a necessidade de responsabilização das empresas detentoras dos dados pessoais dos biohackers, com fulcro nas previsões contidas na Lei Geral de Proteção de Dados - LGPD e na Constituição Federal à luz do princípio da dignidade.

Palavras chave: Microchip Humano; Princípio da Dignidade da Pessoa Humana; Sociedade da Informação; Proteção de Dados Pessoais.

ABSTRACT: This paper analyzes current theme in the face of the 30 years of the Brazilian federal constitution, namely the human microchip, approaching from technical aspects, such as its formation and form of implantation, as well as the consequences of its use for the legal world. It presents the concern about the homeostasis of the constituent onto constitutional when using the human microchip in the face of the personal data stored there, pointing out the possibility that its use generates violations of the rights to intimity, privacy, honor and image, if they are 
marketed or made available without the proper authorization of its owner, demonstrating the need for accountability of companies holding the personal data of biohackers, based on the provisions contained in the General Law on Data Protection - LGPD and the Federal Constitution in the light of the principle of dignity.

Keywords: Human Microchip; Principle of the Dignity of the Human Person; Information Society; Personal Data Protection.

SUMÁRIO: Introdução; 1 Microchip Humano no Mundo Fenômenicodo Século XXI; 1.1Considerações iniciais; 1.2Conceito e forma de utilização do microchip humano; 1.3Dados integrantes no microchip humano e a Lei Geral de Proteção de Dados; 2 O uso do Microchip Humano em face da Constituição Federal brasileira de 1988; 2.1 Aspectos propedêuticos; $2.2 \mathrm{O}$ microchip humano: possível instrumento de violência à Constituição Federal Brasileira de 1988; 2.2.1. O microchip humano e o Princípio da Dignidade da Pessoa Humana; 2.2.2. O microchip humano e a violação a direitos constitucionais; 2.2.3 A utilização do microchip nas relações de emprego como casuística; 3 Alguns aspectos sobre a responsabilização em relação aos dados pessoais dos Microchips Humanos; Conclusão; Referências.

\section{INTRODUÇÃO}

Observa-se que a sociedade passa constantemente por transformações e isso não é novidade, assim como constata-se, dia a dia, facilmente que essas mudanças, especialmente na sociedade da informação alteraram consideravelmente a forma de vida e trabalho das pessoas. Dentro deste contexto fenomênico, as inovações tecnológicas buscam incessantemente facilitar a vida do homem e trazem novidades em diversos aspectos da vida cotidiana quase que diariamente, porém é de se indagar até que ponto essas inovações tecnológicas representam apenas uma consequência natural da transformação da sociedade.

Cabe comentar no presente trabalho e no cenário vivificado pelas tecnologias da informação o uso do microchip humano.

Verifica-se que a citada inovação tecnológica trará comodidade e rapidez nos mais variados campos das relações humanas, vez que não serão mais necessários portar documentos pessoais, cartões de acesso à academia, clube ou do trabalho, e mais que isso, cada indivíduo poderá ter informações médicas registradas no aludido mecanismo traduzido em um chip (constando dados como tipo sanguíneo, doenças anteriores, ficha médica, tratamentos e medicações ministradas). Entretanto, faz-se mister indagar, dentre vários aspectos, v.g. aonde ficarão armazenados todos esses dados e se o local de armazenamento irá conferir segurança total quanto à proteção das informações lá constantes, bem como se direitos e princípios constitucionais não serão alvo de violações.

De toda maneira, observa-se que os questionamentos se centralizam na preocupação da vulneração dos dados pessoais presentes no mencionado microchip - hoje considerados detentores de valor econômico e transformados em commodities.

As citadas reflexões albergam exatamente o mundo novo que se abre aos nossos olhos em face do século XXI, pois muito se fala sobre as vantagens e facilidades decorrentes da tecnologia aplicada nas relações humanas diárias, dando a impressão de que inexiste o lado obscuro concretizados dos riscos e violações legais e constitucionais a ser analisado e transposto na temática referente ao microchip humano.

Por essa razão, o estudo proposto aborda a utilização dos microchips humanos, trazendo inicialmente informações sobre sua estrutura e forma de utilização, sendo na sequência discutida a questão se o seu uso indevido violará ou não o princípio da Dignidade da pessoa humana e 
direitos elencados constitucionalmente, bem como se estes podem ser exigidos nas relações de emprego. Por fim, é tratada a questão referente à responsabilização das empresas detentoras dos dados pessoais dos biohackers, com basenas previsões contidas na Lei Geral de Proteção de Dados - LGPD.

Cabe destacar que para realização do artigo utiliza-se o método dedutivo reflexivo-crítico, enfatizando-se que o tipo de pesquisa realizada consiste na revisão bibliográfica e legislativa que possa fundamentar o desenvolvimento e a conclusão do presente trabalho, objetivando trazer à tona discussão sobre tema tão relevante.

\section{MICROCHIP HUMANO NO MUNDO FENÔMENICO DO SÉCULO XXI}

\subsection{Considerações iniciais}

O emprego do microchip na rotina da sociedade é cada vez maior, a utilização desse dispositivo em animais ou sobre bens, como v.g. cartões de crédito constitui prática tradicional na sociedade hodierna. Assim, é por meio do microchip que a tecnologia é aplicada aos mais diversos setores do país, objetivando trazer facilidades e organização, atingindo desde o mundo animal - hipótese em que pode ser citado o programa denominado "Sistema de Identificação Animal" (ocorrente em Curitiba, o qual aplica o microchip em cães com a finalidade de identificá-los e localizá-los em caso de fuga ou perda ${ }^{1}$ ), até o dia a dia enfrentado pelos seres humanos, hipótese que pode ser mencionada, inclusive, a utilização desse dispositivo para armazenamento de informações relacionadas à saúde do portador do microchip (relatórios médicos, informações de tratamento ou tipo sanguíneo).

A existência e utilização do dispositivo não é novidade, porém a inovação tecnológica que acarreta muita preocupação e atenção para o mundo jurídico é a possibilidade de inserir esse dispositivo em humanos para armazenamento de documentos pessoais para acesso a escritórios, clubes ou academias. Importante avanço tecnológico que muda consideravelmente a forma de vida de muitas pessoas e exigirá maior observância aos direitos constitucionais, notadamente, intimidade, privacidade dos indivíduos que optarem pela inserção nessa realidade.

Vale comentar, ainda, que as pessoas que permitem que esta tecnologia faça parte de seu corpo são conhecidas como biohackers, ou seja, aqueles que compreendem a biologia como algo a ser hackeado, ou seja, entendem que o ser humano pode optar por não ser totalmente humano para o resto da vida e, por isso, autorizam a aplicação das novas tecnologias em seu corpo.

Portanto, consciente de que a sociedade vem mudando suas características constantemente e que tais transformações acarretam significativa insegurança jurídica, principalmente no que se refere ao respeito a direitos constitucionais e ao princípio da dignidade da Pessoa Humana, é necessário compreender as propriedades deste dispositivo e sua forma de funcionamento para fomentar a discussão sobre o tema e buscar fundamentos legais que resguardem os direitos dos biohackers.

\subsection{Conceito e forma de utilização do Microchip humano}

O microchip é um instrumento da área da informática, feito de silicone, que tem como objetivo o armazenamento de inúmeras informações em espaço muito reduzido. É um circuito

\footnotetext{
${ }^{1}$ REDE DE DEFESA E PROTEÇÃO ANIMAL DA CIDADE DE CURITIBA. Amigo é para se cuidar. Disponível em <http://www.protecaoanimal.curitiba.pr.gov.br/Conteudo/Microchip.aspx. $>$ Acesso em: 15 jan. 2018.
}

Revista de Direito Brasileira | Florianópolis, SC | v. 23 | n. 9 | p. 28-49 |Mai./Ago. 2019 
integrado ${ }^{2}$, sendo na realidade um microcircuito eletrônico integrado, "constituído de um código exclusivo e inalterável, marcado com LASER e encapsulado em um vidro cirúrgico e microcoberto em um abrigo de polipropileno biocompatível e antimigratório". 3

Esse circuito integrado é inserido em uma capa de vidro com tamanho próximo ao de um grão de arroz, que possui tecnologia de radiofrequência (RFID), uma vez que o chip RFID permite a transmissão de informação a curta distância ${ }^{4}$. A tecnologia de radiofrequência utilizada nos microchips é a mesma da utilizada nos cartões de crédito, cartões de acesso, celulares e passaportes.

Referido chip humano é implantado na mão de pessoas, entre o dedo indicador e o polegar. Esse implante é feito por meio de uma seringa do mesmo calibre das seringas usadas para doar sangue, podendo ser realizado por médicos (nos casos de microchips implantados exclusivamente para o uso médico) ou por tatuadores (nos demais casos) e o procedimento é rápido, dura cerca de 20 minutos e a partir daí a pessoa já utilizá-lo. Inclusive, é importante frisar que até o presente momento não foram encontrados relatos de reações alérgicas ou rejeição do chip implantando às pessoas.

Oportuno mencionar que existem diferentes marcas de microchip para implantação subcutânea de uso veterinário, porém para uso humano, especialmente com finalidades médicas, existe apenas uma marca, a Verichip:

En la actualidad se pueden encontrar en el mercado, diferentes marcas comerciales de microchips RFID pasivos encapsulados para implantación subcutánea y de uso veterinario como Avid®, Allflex $₫$, DestronFearing ${ }^{\circledR}$, IdentiPet ${ }^{\circledR}, I n f o P E T \AA$, EasyTrac-ID®, entre otros; y solo uno de uso en seres humanos VeriChip ${ }^{\mathrm{TM}}$ (antes de 2009 VeriChip ${ }^{\circledR}$ Corporation, ahora PositiveID®), el cual se encuentra aprobado por la FDA y regulado por la Organización Internacional de Normalización del inglés International OrganizationforStandardization (ISO). ${ }^{5}$

Ademais, importante frisar que um estudo realizado, mostra que cerca de 4.000 pessoas de países como Austrália, China e Rússia já adquiriram o biochip. A ideia está sendo aderida e praticada principalmente na seara internacional, cabendo destacar que no Brasil o tema ainda não ganhou grande repercussão existindo pouquíssimos brasileiros com microchip implantados; Contudo, já se sabe que é algo que tende a crescer significativamente no país, pensando nisso, alguns profissionais de piercing, já foram treinados para realização do procedimento, o qual é muito similar à aplicação de piercing, e que cobram entre $\mathrm{R} \$ 1.000,00$ e $\mathrm{R} \$ 1.200,00$ pelo implante. ${ }^{6}$

Outra questão que merece destaque é a possibilidade de monitoramento dos biohackers, por meio do chip implantado na mão das pessoas, assunto esse que ainda precisa ser apurado de forma técnica e precisa, eis que não existe estudo específico a respeito ou um consenso. De um

\footnotetext{
${ }^{2}$ Microchip traduz-se no conceito de ser composto de "micro + chip "circuito integrado". HOUAISS, Antonio e VILLAR, Mauro de Salles. Dicionário Houaiss da língua portuguesa. Rio de Janeiro: Objetiva, 2001, p. 1916. Ver ainda: Microchip. Disponível em:<https://pt.wikipedia.org/wiki/Microchip>. Acesso em 30 jan..2018

${ }^{3}$ MATTOS, Alessandro Nicoli de. Telemetria e Conceitos relacionados - uma visão geral dos sistemas de telemetria com ênfase em aplicações aeroespaciais. Trabalho disponibilizado como emailware. São José do Campo/SP, 2004, p. 315.

${ }^{4}$ SMITH, Charles. HUMAN MICROCHIP IMPLANTATION. Journal of Technology Management \&Innovation, Santiago, v.3, n.3, p.151-160, 2008. em:<https://scielo.conicyt.cl/scielo.php?script=sci_arttext\&pid=S0718-27242008000100015\&lng=es\&nrm=iso $>$. Acesso em: 20 jun. 2018.

${ }^{5}$ MORENO CORREA, Sandra; MORENO GOMEZ, Freddy y MEDINA CARDENAS, Sebastián. Reacción a cuerpo extraño por implantación de un microchip. Revista Cubana Invest Bioméd [online]. 2015, vol.34, n.1, p. 8092

6 HONORATO, Renata; TOZETTO, Claudia. Biochip, você ainda vai usar um. Disponível em:<https://veja.abril.com.br/tecnologia/biochip-voce-ainda-vai-usar-um/>. Acesso em: 29 de maio 2018.
}

Revista de Direito Brasileira | Florianópolis, SC | v. 23 | n. 9 | p.28-49 |Mai./Ago. 2019 
lado os fabricantes dos microchips garantem que para que o monitoramento possa ser realizado é necessária a existência de um GPS no chip, o que segundo eles inexiste, enquanto que de outro lado, há quem defenda que essa vigilância não necessita do GPS, uma vez que por meio de satélites é possível locar os microchips.

Diante disso, uma coisa é certa, caso seja realmente possível realizar esse monitoramento, haverá inegavelmente um sistema de vigilância completo no Brasil e que será utilizado por instituições comerciais, policiais e judiciárias.

\begin{abstract}
Quando uma pessoa portadora de um chip passa por um local qualquer, equipado com sensores, sua identificação é checada automaticamente, e sua localização confirmada. Sensores nos mais diferentes lugares podem permitir um completo rastreamento das atividades da pessoa que tenha um chip desse tipo implantado em seu corpo. ${ }^{7}$
\end{abstract}

Por fim, deve ser comentado que após ser implantado, o microchip pode ser lido por uma espécie de scanner "que identifica o código do portador e permite acesso através da Internet a um grande banco de dados" ", eis que todos os dados inseridos no microchip são armazenados em um banco de dados do fabricante do microchip.

Dessa forma, será permitido o armazenamento de todos os dados pessoais, fichas médicas, números de cartões e chaves de acesso à diversos locais em um simples chip que está inserido em sua mão e propicia uma maior comodidade às pessoas, pois não precisam carregar consigo todos esses itens.

\title{
1.3 Dados integrantes no microchip humano e a Lei Geral de Proteção de Dados (Lei 13709/2018)
}

O microchip, portanto, é constituído por circuito integrado que também pode ser denominado de chips waferresponsável por armazenar um número infinito de informações. ${ }^{9}$ As informações constantes em cada microchip, dependerão da finalidade escolhida para o implante deste, assim, se inseridos em animais, serão armazenadas no dispositivo informações de identificação (espécie, nome dos donos - no caso dos cães, data da última avaliação feita pelos biólogos - no caso de peixes, tartarugas e outros animais, peso, etc).

Contudo, se implantado nos seres humanos poderá ser utilizado para duas finalidades, quais sejam, a médica e/ou pessoal e nesses casos serão armazenadas informações extremamente sigilosas.

Para o presente estudo, interessa analisar as informações identificadoras constantes em microchips humanos, seja ele utilizado para fins pessoais ou médicos, tais como: número de RG, CPF, título de eleitor, números e senhas de cartão de banco, fichas médicas, tratamentos médicos, medicações utilizadas, doenças anteriores e tipo sanguíneo ${ }^{10}$. Vale destacar que há possibilidade de utilizar os microchips, também, em substituição aos cartões de acesso às empresas, academias, clubes e inclusive em substituição às chaves dos carros, como já acontece na Suécia:

\footnotetext{
${ }^{7}$ REINALDO FILHO. Demócrito. A implantação de chips em seres humanos para uso médico e os riscos à privacidade. Disponível em: <https://www.boletimjuridico.com.br/doutrina/artigo/1450/a-implantacao-chips-sereshumanos-uso-medico-os-riscos-privacidade>. Acesso em 20 jun.2018.

${ }^{8}$ REINALDO FILHO. Demócrito. A implantação de chips em seres humanos para uso médico e os riscos à privacidade. Disponível em: <https://www.boletimjuridico.com.br/doutrina/artigo/1450/a-implantacao-chips-sereshumanos-uso-medico-os-riscos-privacidade>. Acesso em 20 jun.2018.

9 DISCOVERY BRASIL. Marcos da Tecnologia - Microchip. Disponível em:<http://www.oarquivo.com.br/variedades/ciencia-e-tecnologia/2507-marcos-da-tecnologia-microchip.html $>$. Acesso em: 01 jun.2018.

${ }^{10}$ REINALDO FILHO, Demócrito. A implantação de chips em seres humanos para uso médico e os riscos àprivacidade. Disponível em: $<$ https://www.boletimjuridico.com.br/doutrina/artigo/1450/a-implantacao-chips-sereshumanos-uso-medico-os-riscos-privacidade>. Acesso em: 20 jun. 2018.
}

Revista de Direito Brasileira | Florianópolis, SC | v. 23 | n. 9 | p. 28-49 |Mai./Ago. 2019 
Em uma das iniciativas, usuários de uma academia trocaram o cartão de identificação pelo microchip para entrar no local. Em outra, de maior porte, a empresa nacional de transporte ferroviário, SJ, passou a usar os chips biométricos para identificar os usuários e cobrar automaticamente as tarifas de embarque de sua carteira virtual.

Desse modo, verifica-se que constarão nos microchips humanos, dados pessoais, ou seja, qualquer informação que possa identificar exatamente determinada pessoa, cabendo relembrar que mencionadas informações dos biohackerssão armazenadas em grandes bancos de dados da empresa fornecedora do dispositivo.

Os dados informacionais que circulam pelas redes são divididos em duas categoriais: dados pessoais ou também denominados de identificáveis e dados sensíveis. A distinção feita entre eles baseia-se na detecção da finalidade e da natureza do tratamento informacional, ou seja, pela percepção da capacidade do dado em se relacionar a uma pessoa e a ela gerar danos.

Referente ao tema em pauta, a Lei 13.709/2018 trouxe novas definições e disposições relevantes às instituições de caráter público como privada, no que concerne ao tema sobre tratamento de informações definidas como dados pessoais. Considera-se inegável a importância de seu impacto no ordenamento jurídico pátrio, posto que trouxe em seu contexto a regulamentação referente a conceitos, princípios aplicados ao tratamento de dados pessoais, penalidades e responsabilidades.

Assim, baseado no conceito constante na LGPD (Lei n. 13.709/2018), mais especificamente no artigo $5^{\circ}$, é possível verificar mencionada distinção entre dados pessoais e dados sensíveis, uma vez que:

I - dado pessoal: informação relacionada a pessoa natural identificada ou identificável;

II - dado pessoal sensível: dado pessoal sobre origem racial ou étnica, convicção religiosa, opinião política, filiação a sindicato ou a organização de caráter religioso, filosófico ou político, dado referente à saúde ou à vida sexual, dado genético ou biométrico, quando vinculado a uma pessoa natural.

Portanto, toda a informação que se relaciona a uma pessoa identificada ou identificável que não se limite a aspectos como nome, sobrenome, apelido, idade, endereço residencial ou eletrônico, perfil consumerista, histórico escolar, entre outros, pode ser considerado como dados pessoais, enquanto os dados pessoais sensíveis, caracterizam-se como dados inerentes à "personalidade do indivíduo e suas escolhas pessoais". ${ }^{11}$

Observando-se, ainda, que segundo mencionada lei, existe uma terceira categoria de dados informacionais denominados dados anonimizados, ou seja, aqueles relativos a um titular que não podem ser identificados (art. $5^{\circ}$, inciso III).

É oportuno frisar que o objeto da Lei Geral de Proteção de Dados é proteger direitos fundamentais de liberdade e privacidade, bem como o livre desenvolvimento da personalidade da pessoa. Em razão disso, o respeito à privacidade; a inviolabilidade da intimidade, honra e imagem; a dignidade são fundamentos da legislação de proteção de dados. Portanto, os agentes de tratamento dos dados contidos nos microchips deverão respeitar todas as determinações previstas na mencionada lei, adequando-se o quanto antes à LGPD, sob pena de multa.

Pelos motivos acima, observa-se o cunho principiológico da lei, fortalecendo os direitos constitucionais já mencionado sob a égide procedimental adequada aos modelos de negócios estruturados segundo o art. 170 da Constituição Federal de 1988. Assim, no art. $5^{\circ}$ traz de forma objetiva e peremptória princípios de inegável importância ao tema ora estudado: a) licitude; b) lealdade; c) transparência; d) limitação da finalidade; e) minimização dos dados; f) exatidão; g)

11 PINHEIRO, Patrícia Peck. Proteção de dados pessoais: comentários à Lei n.13.70/2018. Saraiva: São Paulo, 2018 , p. 25.

Revista de Direito Brasileira | Florianópolis, SC | v. 23 | n. 9 | p.28-49 |Mai./Ago. 2019 
limitação da conservação; h) integridade e confidencialidade (segurança informacional); i) responsabilidade.

Para além disso, a lei em estudo propugna princípios fundamentais relativos ao tratamento de dados pessoais assim elencados: a) finalidade do tratamento; b) compatibilidade do tratamento com as finalidades informadas ao titular; c) limitação do tratamento ao mínimo necessário para a realização de suas finalidades; d) garantia aos titulares, de consulta facilitada e gratuita sobre a forma do tratamento; e) garantia, aos titulares, de consulta facilitada e gratuita sobre a forma de tratamento; f) garantia, aos titulares, de exatidão, clareza, relevância e atualização dos dados, de acordo com a necessidade e para o cumprimento da finalidade de seu tratamento; g) transparência aos titulares; h) utilização de medidas técnicas e administrativas aptas a proteger os dados pessoais; i) prestação de contas, pelo agente, da adoção de medidas capazes de comprovar a proteção de dados pessoais.

Importante salientar que o tema referente à proteção de dados pessoais também recebeu tratamento com o Regulamento Europeu na União Europeia. Portanto, interessante será a hipótese na qual uma pessoa jurídica nacional que capte dados no Brasil detendo aplicativo que autorize o usuário do serviço e titular de dados de qualquer nacionalidade e residência na União Europeia que utiliza v.g. cartão de crédito internacional, ${ }^{12}$ atrairá a aplicação de leis e jurisdição para sua operação, tanto a lei de proteção de dados nacional (LGPD) como a europeia (GDPR).

Assim, vê-se que a Lei de proteção de dados Europeia (GDPR) que passou a ser aplicada a partir de 25 de maio de 2018 veio com o objetivo de facilitar os negócios para as empresas em toda a União Europeia, a fim de que possam aproveitar de forma plena a economia digital em toda a sua abrangência territorial. Através de seu regulamento, as empresas que pretendam expandir-se para outro país da UE estarão sujeitas ao mesmo conjunto de regras, "não tendo de suportar custos adicionais relativos a aconselhamento jurídico e, uma vez que deixam de existir as obrigações de notificação, não terão de pagar taxas de notificação". ${ }^{13}$

Analisando-se o Regulamento Europeu, percebe-se que este passou a impor que os demais países e empresas que objetivassem estabelecer relações comerciais com a União Europeia deveriam ter uma legislação em paralelo e com os traços nivelares do citado diploma, a fim de que não tivessem dificuldade de realizar negócios com os países europeus. Portanto, o Brasil mesmo possuindo o Marco Civil da Internet não tinha critérios concentrados e adequados para a indicação precisa sobre o tratamento de dados dentro de padrões de segurança informacional, impulsionando assim o advento da Lei 13.709/2018, tendo dezoito meses como prazo inicial estabelecido para adaptação a partir de sua promulgação em 14 de agosto de 2018.

Notadamente em relação à comparação entre os diplomas legais, observa-se que no que tange à definição de dados pessoais e sensíveis, o Regime Europeu adotou os mesmos princípios e conceitos dos citados dados, acrescentando observações sobre dados genéticos, biométricos e inerentes à saúde (artigo 4. $^{\circ}$, n. $^{\circ} 1$ do Regulamento)

Diante da inclusão de informações confidenciais armazenadas nesses bancos de dados, bem como do conhecimento do valor da informação para a sociedade da informação, resta imprescindível destacar a necessidade da observância a direitos constitucionais presentes na Carta Magna de 1988 e da diretriz básica constante na Lei 13.709/2018 no que tange à ideia de que para o tratamento de dados pessoais é de inegável importância o consentimento ${ }^{14}$ do titular que deverá ser devidamente vinculado às finalidades declaradas pelo titular/usuário previstos no

\footnotetext{
12 Exemplo mencionado por Patrícia Peck Pinheiro. Proteção de dados pessoais: comentários à Lei n.13.70/2018, Saraiva: São Paulo, 2018, p. 38.

${ }^{13}$ COMISSÃO EUROPEIA. Reforma em matéria de proteção de dados na UE:regras melhores para as empresas europeias. Disponível em: < https://ec.europa.eu/commission/sites/beta-political/files/data-protection-factsheetbusiness_pt.pdf>. Acesso em 18 de dezembro de 2018.

14 Deve-se observar que na Lei Geral de Proteção de Dados Europeia, os titulares além de terem direito a informações claras e acessíveis durante todo o tratamento de dados, poderá revogar o seu consentimento a qualquer momento (arts. 12 a 14 do Regulamento Europeu).
}

Revista de Direito Brasileira | Florianópolis, SC | v. 23 | n. 9 | p. 28-49 |Mai./Ago. 2019 
art. $7^{\circ}$ do diploma mencionado, como: cumprimento de obrigação legal ou regulatória pelo controlador; para a proteção da vida do titular ou de terceiro; para o exercício regular de direitos em processo judicial, arbitral ou administrativo; para o cumprimento da execução de contrato ou de procedimentos preliminares referentes a contrato do qual o titular seja parte a pedido do titular de dados; para a proteção de crédito e para atender aos interesses legítimos do controlador ou de terceiro.

Em conclusão, todo agente deverá indicar a finalidade e justificação do uso do tratamento do dado, garantindo a sua utilização apenas nas hipóteses acima preconizadas.

No Regulamento Europeu (GDPR) observa-se que além de prever a necessidade do uso do dado segundo a finalidade indicada, agrega exceções de tratamento por razões de interesse público, segurança e saúde ${ }^{15}$.

\section{O USO DO MICROCHIP HUMANO EM FACE DA CONSTITUIÇÃO FEDERAL BRASILEIRA DE 1988}

\subsection{Aspectos propedêuticos}

Atualmente todas as pessoas fazem parte de uma rede que reduz a códigos e dados a partir do momento em que nela lançam suas informações que são armazenadas em "nuvens". As citadas "nuvens", por sua vez, têm pilares no hardware, local esse repleto de códigos que, uma vez munido das ferramentas devidamente qualificadas, autoriza o acesso total aos mesmos. Portanto, a partir dessa hipótese fática pode ocorrer violação a direitos e princípios constitucionais.

Desse modo, a análise crítico-reflexiva sobre o uso do microchip humano deita raízes sobre o questionamento desta nova realidade digital sob o viés da Constituição Federal Brasileira nascida há 30 anos.

\subsection{O microchip humano: possível instrumento de violência à Constituição Federal Brasileira de 1988}

A sociedade atual vive em um momento pautado em uma "biopolítica de modulação de comportamentos, há uma troca conflitiva entre a expansão da microeconomia da interceptação de dado, a intrusão de dispositivos de rastreamento e o direito à privacidade" "16, uma vez que a informação passou a ser um insumo importante e valioso à economia.

Assim, quem detém o poder, indiscutivelmente é quem detém informações, fato este que desencadeou a busca desenfreada pela coleta de dados pessoais e demonstra a necessidade de discussão sobre o direito da privacidade e intimidade dos biohackers.

Ocorre que, em muitos casos, o uso desmensurado e sem parâmetros condicionadores das informações implica na violação a direitos constitucionais, notadamente intimidade e privacidade, além do princípio da dignidade da Pessoa Humana.

\subsubsection{O microchip humano e o Princípio da Dignidade da Pessoa Humana}

\footnotetext{
${ }^{15}$ COMISSÃO EUROPEIA. Reforma em matéria de proteção de dados na UE: proteção de dados reforçada para os cidadãos europeus. Disponível em https://ec.europa.eu/commission/sites/beta-political/files/data-protectionfactsheet-citizens_pt_0.pdf. Acesso em 02 de dezembro de 2018.

16 SILVEIRA, Sergio Amadeu da. Tudo sobre tod@s: redes digitais, privacidade e venda de dados pessoais.São Paulo: Edições Sesc São Paulo, 2017, p. 98 .
} 
A dignidade da pessoa humana foi tema que resultou muito desenvolvido após a Segunda Guerra Mundial quando do processo de reconstrução da ordem internacional. Assim, pode ser demonstrada na Carta das Nações Unidas de 1945 que estabelece o desiderato das nações em "desenvolver a fé nos direitos fundamentais, a dignidade e o valor do ser humano".

Nesse modelo de pensamento, a dignidade se manifesta como valor. Nas palavras de Pasquale Policastro ${ }^{17}$ trata-se de uma valor transformativo, pois com a introdução da noção de dignidade no artigo 1 da Lei Fundamental alemã houve grande transcendência na sanção legal do renascimento e transformação do regime alemão (foi a primeira a acolher como princípio fundamental a dignidade em seu sistema), visto que se passou a compreender a dignidade como um conceito presente na Constituição, entendido como um pacto racional entre os poderes políticos/nações, objetivando-se que todos eles estivessem de acordo com este valor.

Nesse cenário, a proteção da dignidade humana, expressada no direito internacional ou no direito constitucional estatal, facilitou o caminho ao enfoque da necessidade da busca de aspectos relevantes da existência humana e de garantias de proteção independentes de modelos de direitos humanos perfilhados e estabelecidos em ordenamentos constitucionais.

Passou-se através da proteção da dignidade à própria busca da proteção do humano. Dessa feita, objetivando-se uma proteção integral e internacional, a Declaração Universal dos Direitos Humanos de 1948 passou a assinalar que: "Todos os seres humanos nascem livres e iguais em dignidade e direitos e, dotados como estão de razão e consciência, devem comportar-se fraternalmente uns com os outros".

O citado documento influenciou diversos modelos constitucionais tendentes à exortação da proteção dos direitos humanos e à reconstrução da ordem internacional.

No Brasil passou a ser reconhecido no art. $1^{\circ}$, inciso III da Constituição Federal de 1988, sendo considerado o princípio-matriz de toda a organização social, política, econômica e cultural de um país, objetivando a proteção do homem e estabelecendo garantias institucionais tendentes a garantir a eficácia dos direitos fundamentais.

A constitucionalização do princípio em pauta impõe a necessária ideia de ser ele o elemento fundante de todo o ontosconstitucional, levando à conclusão que a elaboração do Direito, bem como a sua interpretação devem a ele vincular-se, assegurando condições existenciais que o permitam atingir os fins colimados na Carta Magna de 1988.

O microchip humano resvala no princípio constitucional da dignidade da pessoa humana que conforme Habermas ${ }^{18}$ apresenta como modelo contemporâneo as ideias de dignidade como valor de todos os seres humanos e segundo, como o fundamento dos direitos fundamentais. No que tange ao primeiro aspecto, a dignidade seria um valor inerente e absoluto ao ser humano, e em relação ao segundo, os direitos humanos teriam sua razão de ser e sua justificação na proteção e desenvolvimento da dignidade.

Aproveitando-se das lições de Kant, observa-se que a pessoa deve ser tida como um fim e nunca um meio, distinguindo no mundo o que é passível de preço e o que tem dignidade, ressaltando-se que o que tem preço pode ser avaliado e substituído ou trocado por outra coisa de igual valor ${ }^{19}$. De outra parte, a dignidade não tem valoração, pois é possuidora de valor absoluto, apresentando a qualidade ou atributo intrínseco de sobrepor-se a qualquer avaliação ou determinação de preço.

Portanto, a dignidade atribui um valor intrínseco ao ser humano, independentemente de qualquer conduta e valor fundante de qualquer sistema jurídico.

\footnotetext{
${ }^{17}$ POLICASTRO, Pasquale. Dignidad de la persona y principios constitucionales en la época de la globalización. Revista Persona y Derecho, Universidad de Navarra:Pamplona, v. 64, 2011, p. 191.

${ }^{18}$ HABERMAS, Jürgen. Human Dignity and the Realistic Utopia of Human Rights. Metaphilosohyy, v. 41, n. 4, July 2010, p. 465-466.

${ }^{19}$ KANT, Immanuel - Fundamentação da metafísica dos costumes e outros escritos; tradução de Leopoldo Holzbach - São Paulo: Martin Claret, 2004
}

Revista de Direito Brasileira | Florianópolis, SC | v. 23 | n. 9 | p. 28-49 |Mai./Ago. 2019 
Nesse sentido, vale lembrar as lições trazidas por Greice Patrícia Fuller para quem a dignidade da Pessoa humana apesar de ser reconhecida como conceito a priori, teve sua definição expressa na Constituição Federal de 1988 como o valor- matriz dos fundamentos da República Federativa do Brasil. Portanto, a citada autora conclui que a dignidade não pode deixar de ser entendida como um "valor fundamental de toda ordem sistêmica refletida no conjunto ideológico presente na citada Carta Magna, assim entendendo a ordem jurídica, político-administrativa, tributária, econômico-financeira, cultural e social" 20

Peces-Barba ${ }^{21}$ informa de forma peremptória que o "fundamento de la ética pública de la modernidad, como unprius de los valores políticos y jurídicos y de los principios que derivan de esos valores". No mesmo sentido, vem Garzón Valdés ${ }^{22}$ que afirma a dimensão social da dignidade humana quandopropõe a ideia de ser "el punto de partida para toda reflexión acerca de las reglas de convivencia humana que pretendan tener alguna justificación moral".

Assim, o homem é digno pelo simples fato de ser igual em sua humanidade. Assim, foram os pensamentos germinais de RecasensSiches ${ }^{23}$, LegazLacambra ${ }^{24}$, Gómez Arboley ${ }^{25}$ e outros, considerando a existência de uma dignidade intrínseca capaz de conceber ao homem direitos que lhe são inerentes e básicos à convivência fraternal dos homens em sociedade.

Segundo Ingo Sarlet ${ }^{26}$ toda a atividade estatal e todos os órgãos públicos encontram-se vinculados ao princípio da Dignidade da Pessoa Humana, impondo-lhes a um só tempo um dever de respeito e proteção que se exprime tanto na obrigação de o Estado abster-se de ingerências na esfera individual, quanto no dever de protegê-lo contra agressões de terceiros.

Entretanto, faz-se necessário gizar que tal eficácia positiva e negativa do princípio da dignidade da pessoa humana também deve ser verificada em nível de atividades privadas para que se possa concretizar a ideia de conceber a Constituição como documento calcado em uma unidade axiológica material e coerente.

Tecidas as observações acima, percebe-se claramente o inequívoco elo existente entre a temática sobre microchip humano e o princípio da Dignidade da Pessoa Humana.

Tomando-se por efeito os ensinamentos de García de Enterría ${ }^{27}$ y Pérez Luño ${ }^{28}$, o conceito de dignidade caracteriza-se como "valor superior" a serviço da própria Constituição Federal.

Nesse diapasão, observa-se que o se de um lado o microchip humano pode ser usado como gerador constante de dados pessoais acessíveis de forma simples e rápida, de outro, é possível imaginar de forma lógica e reflexiva a possibilidade do uso indevido de tais dados para fins ilícitos ou não permitidos por seu portador, como o que será analisado em tópico sobre as relações de trabalho, v.g.

${ }^{20}$ FULLER, Greice Patricia. O meio ambiente hospitalar em face da Dignidade da Pessoa Humana no Direito Ambiental Brasileiro. Revista Brasileira de Direito Ambiental, abr/jun 2011, p. 62

${ }^{21}$ PECES-BARBA, Gregorio. La dignidad de la persona desde la filosofía del derecho. Cuadernos Bartoloméde las Casas. Madrid: Dykinson, 2003, p. 12.

${ }^{22}$ GARZÓN VALDÉS, Ernesto. Tolerancia, dignidad y democracia. Universidad Inca Garcilaso de la Vega. Lima: Fondo Editorial, 2006, p. 260.

${ }^{23}$ RECASENS SICHES, Luis. Vida humana, sociedade y Derecho, p. 251 Disponível em <. http://www.biblioteca.org.ar/libros/89607.pdf>. Acesso em: 05 ago.2017.

${ }^{24}$ LEGAZ LACAMBRA, Luis. La noción jurídica de la persona y los derechos del hombre. In: Revista de Estudios Políticos, XI, Madrid: Instituto de Estudios Políticos, 1955, p. 15-46.

${ }^{25}$ GÓMEZ ARBOLEYA, E. Sobre la noción de persona. Revista de Estudios Políticos, num. 47. Madrid: Instituto de Estudios Politicos, 1949, p. 104-133.

${ }^{26}$ SARLET, Ingo Wolfgang. A eficácia dos direitos fundamentais. Porto Alegre: Livraria do Advogado, 1998, p. 110.

${ }^{27}$ GARCÍA DE ENTERRÍA, Eduardo. La Constitución como norma y el Tribunal Constitucional. Navarra: Thomson-Civitas, 2006, p. 207.

${ }^{28}$ PEREZ LUÑO, Antonio Enrique. Los derechos fundamentales. Madrid: Tecnos, 1998, p. 58 e 174-177. Revista de Direito Brasileira | Florianópolis, SC | v. 23 | n. 9 | p.28-49 |Mai./Ago. 2019 
Isso porque, as informações constantes nos dados dos microchips são possuidores de valor social e econômico dentro do que se vivencia na sociedade pós-moderna e, consequente economia dita informacional do século XXI.

Para Castells, em razão da transformação da sociedade surge uma economia informacional, global e em rede, a qual gira em torno da informação:

Uma nova economia surgiu em escala global no último quartel do século XX. Chamo-a de informacional, global e em rede para identificar suas características fundamentais e diferenciadas e enfatizar sua interligação. É informacional porque a produtividade e a competitividade de unidades ou agentes nessa economia (sejam empresas, regiões ou nações) dependem basicamente de sua capacidade de gerar, processar a e aplicar de forma eficiente a informação baseada em conhecimentos. É global porque as principais atividades produtivas, o consumo e a circulação, assim como seus componentes (capital, trabalho, matéria-prima, administração, informação, tecnologia e mercados) estão organizados em escala global, diretamente ou mediante uma rede de conexões entre agentes econômicos. É rede porque, nas novas condições históricas, a produtividade é gerada, e a concorrência é feita em uma rede global de interação entre redes empresariais. Essa nova economia surgiu no último quartel do século XX porque a revolução da tecnologia da informação forneceu a base material indispensável para sua criação ${ }^{29}$.

No século XXI, o sistema capitalista passou, portanto, por uma reestruturação em seu modo de produção e houve a criação de uma nova estrutura social, a qual foi denominada por Castells como informacionalismo. Assim, a informação passa a ser a mercadoria mais valiosa para a sociedade da informação, a primeira característica deste novo cenário é a de que "a informação é sua matéria prima: são tecnologias para agir sobre a informação, não apenas informação para agir sobre a tecnologia, como foi o caso das revoluções tecnológicas anteriores" 30 .

Em escala global, muitos sustentam que os dados e a informação ocupam um lugar de destaque e importância para a sociedade, que podem ser considerados o verdadeiro petróleo da era digital, conforme destacado em reportagem publicada em 06 de maio de 2017 pela revista The Economist, "A centuryago, theresource in questionwasoil. Now similar concerns are being raised by the giants that deal in data, the oil of the digital era."

Assim, é inegável a conclusão de que a informação é fonte de produção de riquezas e que a busca pelo delineamento do perfil e comportamento dos usuários de microchip permitirá a oferta de produtos, publicidade, propagandas políticas, planos de saúde específicos e usos indevidos dos dados com o fim de gerar e capacitar geradores atividades ilícitas por quem detiver tais dados.

Dessa maneira, observa-se que na casuística exposta, o princípio da dignidade da pessoa humana é violado em seu objetivo de constituir garantia contra práticas que acolhem formas de degradação humana e poderio autoritário de opções políticas e econômicas de exclusão e miséria.

O homem passa a ter um preço e portanto, ser um mero meio para consecução de fins econômicos ou políticos.

\subsubsection{O microchip humano e a violação a direitos constitucionais}

\footnotetext{
${ }^{29}$ CASTELLS, Manuel. A Era da informação: economia, sociedade e cultura. Volume 1. A sociedade em Rede, 10. ed., São Paulo: Paz e Terra, 2007, p. 68

${ }^{30}$ Ibidem, p. 32.

31 The Economist. The world's most valuable resource is no longer oil, but data.Disponível em <https://www.economist.com/leaders/2017/05/06/the-worlds-most-valuable-resource-is-no-longer-oil-but-data> . Acesso em: 01jun.2018.
}

Revista de Direito Brasileira | Florianópolis, SC | v. 23 | n. 9 | p. 28-49 |Mai./Ago. 2019 
Como afirma Greice Patrícia Fuller, não há como desvincular o conceito de dignidade da pessoa humana com o de direitos fundamentais constitucionais e por consequência, a ideia imperativa de que as atividades sociais, econômicas e culturais devam ser executadas segundo essa diretriz principiológica. ${ }^{32}$

Portanto, os valores de liberdade e igualdade, bem como solidariedade (fraternidade) possuem como fim último a proteção do desenvolvimento da noção de dignidade humana.

Nota-se claramente que a dignidade da pessoa humana é fundamento dos princípios da liberdade, igualdade, intimidade e privacidade. Assim, a noção de dignidade compreende a noção de valor constitucional supremo que, conforme entendimento de Alexy, a proteção à liberdade e à dignidade são princípios constitucionais que não somente tem aplicação na relação entre o Estado e os cidadãos, mas também em todos os âmbitos do Direito, produzindo um efeito de "irradiação sobre todo o sistema jurídico"33.

$\mathrm{O}$ direito à privacidade e à intimidade são direitos constitucionais (e da personalidade) e estão garantidos na Declaração Universal dos Direitos Humanos, na Constituição Federal e no Código Civil. Na Declaração dos Direitos Humanos de 1948 verifica-se a impossibilidade de interferência na vida privada do homem e no Código Civil, há um capítulo específico para tratar do tema e assim faz nos seus artigos 11 ao 21 .

Importante mencionar que direito à personalidade é direito fundamental, ou seja, um direito aplicado diretamente, que goza de uma proteção especial na Constituição Federal. Por essa razão, está prevista no artigo $5^{\circ}$, inciso $\mathrm{X}^{34}$ da Carta Magna, a proteção à privacidade, em sentido amplo, referindo-se a manifestações da esfera íntima, privada e da personalidade da pessoa., o que permite concluir que "a vida social dos indivíduos não possui somente dois espaços, o público e o privado, pois neste se opera nova subdivisão, entre a intimidade e a privacidade". 35

Assim, o direito à intimidade e à privacidade compõem o direito à personalidade, porém é de se observar a distinção entre intimidade e privacidade:

Podemos vislumbrar, assim, dois diferentes conceitos. Um, de privacidade, onde se fixa a noção das relações interindividuais que, como as nucleadas na família, devem permanecer ocultas ao público. Outro, de intimidade, onde se fixa uma divisão linear entre o "eu" e os "outros" de forma a criar um espaço que o titular deseja manter impenetrável mesmo aos mais próximos. Assim, o direito de intimidade tem importância e significação jurídica na proteção do indivíduo exatamente para defende-lo de lesões a direitos dentro da interpessoalidade da vida privada. ${ }^{36}$

O direito à intimidade visa proteger o íntimo da pessoa, aquilo que não é de conhecimento de terceiros, cabendo somente ao próprio indivíduo, enquanto a privacidade é entendida como

\footnotetext{
32 FULLER, Greice Patrícia. A responsabilidade social e ambiental das entidades financeiras em face do Direito Ambiental como direito humano e da sociedade da informação. Revista da Faculdade de Direito Universidade Federal de Minas Gerais, n. 71, jul/dez.201, p.217.

${ }^{33}$ ALEXY, Robert. Derechos fundamentales, ponderación y racionalidad. In: FÉRNANDEZ SEGADO, F. (ed). The Spanish Costitution in the European Constitutional Context/La Constitución Española en el Contexto Constitucional Europeo. Madrid: Dykinson, 2013, p. 1507.

${ }^{34}$ Art. $5^{\circ}$ Todos são iguais perante a lei, sem distinção de qualquer natureza, garantindo-se aos brasileiros e aos estrangeiros residentes no País a inviolabilidade do direito à vida, à liberdade, à igualdade, à segurança e à propriedade, nos termos seguintes:

X - são invioláveis a intimidade, a vida privada, a honra e a imagem das pessoas, assegurado o direito a indenização pelo dano material ou moral decorrente de sua violação;

${ }^{35}$ ARAUJO, Luiz Alberto David; NUNES JUNIOR, Vidal Serrano. Curso de Direito Constitucional.12 ed. São Paulo: Saraiva, 2008. p. 152.

${ }^{36}$ Ibidem.
}

Revista de Direito Brasileira | Florianópolis, SC | v. 23 | n. 9 | p.28-49 |Mai./Ago. 2019 
tudo o que não pertença ao âmbito da intimidade, mas que, por sua vez, não transparece à esfera pública. $^{37}$

Todavia, o conceito de privacidade apresentado por esses diplomas teve que ser adaptado para acompanhar as transformações da sociedade, que colocam em risco, justamente esse direito constitucional, como explica Patrícia Scorzelli:

\begin{abstract}
A necessidade de uma tutela jurídica da vida privada tornou-se ainda mais premente com o advento da era tecnológica e com as novas possibilidades abertas à invasão da intimidade. A tecnologia destina-se, em primeira análise, ao enriquecimento da personalidade humana, à ampliação da capacidade de domínio sobre a natureza, aprofundamento do conhecimento e disseminação da riqueza, revelando e promovendo novos rumos de acesso ao conforto. Seus efeitos, todavia, propagam-se das mais diversas e indesejadas formas. ${ }^{38}$
\end{abstract}

Em razão do citado raciocínio e baseado noontos constitucional, a Lei no 13.709/2018 (denominada LGPD) traz como um dos fundamentos do uso da internet no Brasil, a proteção da privacidade (art. $2^{\circ}$, inciso I). Assim, resta garantido o direito à privacidade nas comunicações, que é condição para o pleno exercício do direito de acesso à internet, e no que pertine à tratamento dos dados, como: qualquer operação de coleta, armazenamento, guarda etc,em que pelo menos um desses atos ocorra em território nacional, há determinação da obrigatoriedade de respeitar a legislação brasileira.

Isso porque, conforme artigo $3^{\circ}$ da mencionada lei é aplicado a qualquer operação de tratamento de dados desde que ocorra em território nacional ou que tenha por objetivo a oferta ou fornecimento do tratamento de dados de indivíduos localizados em território nacional (mesmo que a empresa seja estrangeira), ou ainda, que os dados pessoais tenham sido coletados no território nacional.

Desse arcabouço nota-se a demonstração que "a obrigação de fornecer dados não pode ser simplesmente considerada como a contrapartida dos benefícios sociais que, direta ou indiretamente, o cidadão pode chegar a aproveitar". 39

$\mathrm{O}$ entendimento, ademais, deve ser compreendido no sentido de que o direito à proteção de dados pessoais no ordenamento jurídico brasileiro é considerado um direito fundamental, que como denota Ingo Sarlet, abarca as questões:

\begin{abstract}
a) o direito de acesso e conhecimento dos dados pessoais existentes em registros (banco de dados) públicos e privados; b) direito ao não conhecimento, tratamento e utilização e difusão de determinados dados pessoais pelo Estado ou por terceiros, aqui incluído um direito de sigilo quanto aos dados pessoais; c) direito ao conhecimento da identidade dos responsáveis pela coleta, armazenamento, tratamento e utilização dos dados; d) o direito ao conhecimento da finalidade da coleta e eventual utilização dos dados; e) direito a retificação e, a depender do caso, de exclusão de dados pessoais armazenados em banco de dados. ${ }^{40}$
\end{abstract}

Na temática referente ao uso de microchip humano, portanto, verifica-se que o indivíduo perde a privacidade e sua vida íntima, de certa forma, deixam estes direitos de serem seus, uma vez que o Estado ou qualquer pessoa jurídica de direito privado é detentor do maior número possível de dados do cidadão. Isso acontece porque os dados possuem valor significativo para a sociedade da informação e como já exposto, verdadeira fonte de riqueza.

\footnotetext{
${ }^{37}$ ALONSO, Felix Ruiz. Direito à privacidade. Porto Alegre: Síntese, 2004. p. 457.

${ }^{38}$ SCORZELLI, Patrícia. A comunidade Cibernética e o Direito. Rio de Janeiro: Lumen Juris, 1997. p. 23.

${ }^{39}$ RODOTÁ, Stefano. A vida na sociedade da Vigilância - a privacidade hoje. Rio de Janeiro: Renovar, 2008. p. 36.

${ }^{40}$ MARINONI, Luis Guilherme; MITIDIERO, Daniel; SARLET, Ingo Wolfgang. Curso de Direito Constitucional. São Paulo: Revista dos Tribunais, 2014. p. 434/435.
} 
Atualmente, quem detém a informação (bem de mais valia da sociedade) é o detentor do poder, porém não é possível permitir que os detentores de informações (que no caso em tela são os responsáveis pelos bancos de armazenamento de dados dos biohackers) violem direitos fundamentais de terceiros para alcançar vantagem econômica. Entre a proteção de garantias fundamentais e a obtenção de ganho econômico, deverá prevalecer as determinações constantes na Constituição Federal.

Portanto, verifica-se que os dados armazenados nos microchips utilizados pelos biohackers, devem ser protegidos e não poderão ser comercializados ou expostos, sem a autorização dos respectivos proprietários, sob pena de violação a direitos constitucionais, haja vista que no Brasil, a vida privada de qualquer pessoa natural é protegida como um direito constitucionais, especialmente de intimidade, privacidade e liberdade.

A Constituição Federal estabelece proteção ao que é particular, ou seja, proíbe a violação a aspectos que dizem respeito ao ser humano de forma individualizada, que "ninguém mais temdireito de conhecer, de explorar ou expor" 41 . Mencionada proteção pode ser observada por meio dos direitos à honra, imagem e liberdade, considerados direitos fundamentais de primeira geração.

Urge salientar sobre o mencionado ponto que a doutrina classifica os direitos fundamentais em gerações ou dimensões (sendo essa nomenclatura adotada pela doutrina mais atual). Na primeira dimensão estão inseridos os direitos ligados ao princípio da liberdade, são direitos civis e políticos; enquanto que na segunda dimensão estão aqueles atrelados ao princípio da igualdade, direitos econômicos sociais e culturais; e na terceira dimensão estão os direitos fundamentais relacionados à solidariedade, aqueles transindividuais, tais como direito ao desenvolvimento, comunicação e meio ambiente equilibrado ${ }^{42}$.

Além dessas gerações, ainda há direitos fundamentais de quarta e quinta dimensões, segundo Paulo Bonavides, sendo que na quarta dimensão estão os direitos fundamentais decorrentes da globalização, como v.g.: informação e democracia, enquanto que na quinta dimensão está o supremo direito da humanidade, qual seja: o direito à paz. ${ }^{43}$

Dessa forma, uma vez que os direitos tratados nesse momento se referem à direitos do indivíduo, direitos civis, esses são considerados direitos de primeira dimensão. Oportuno, portanto, fazer uma breve análise sobre cada um deles, iniciando pelo direito à honra. $\mathrm{O}$ conceito de honra está totalmente relacionado à proteção da dignidade da pessoa humana e segundo Adriano de Cupis, pode ser entendida como:

tanto o valor moral íntimo do homem como a estima dos outros, ou a consideração social, o bom nome ou a boa fama, como, enfim, o sentimento, ou consciência da própria dignidade pessoal a dignidade pessoal refletida na consideração dos outros e no sentimento da própria pessoa. ${ }^{44}$

Assim, o direito à honra que visa proteger a dignidade pessoal e reputação do indivíduo , está previsto no artigo $5^{\circ}$, inciso X, da Constituição Federal e pode ser observado de duas formas: i) honra subjetiva, que se refere ao sentimento que a pessoa tem por si mesma e ii) honra objetiva, aquela que se refere ao conceito da sociedade sobre o indivíduo.

Nota-se também que o citado direito pode ser alvo de violação quando do uso indevido do microchip, pois aproveitando-se de alguma informação obtida nos dados da pessoa que o porta, pode ensejar danos à sua honra seja objetiva ou subjetiva.

\footnotetext{
${ }^{41}$ NERY, Nelson. Constituição Federal anotada e explicada. 5. ed. Rio de Janeiro: Forense, 2012. p. 18.

${ }^{42}$ FACHIN, Zulmar. Curso de Direito Constitucional. 5. ed. Rio de Janeiro: Forense, 2012, p. 224-226

${ }^{43}$ Ibidem, p. 593.

44 CUPIS, Adriano de. In ARAUJO, Luiz Alberto David; NUNES JUNIOR, Vidal Serrano. Curso de DireitoConstitucional. 12 ed. São Paulo: Saraiva, 2008. p. 154
} 
Nesse tocante e em relação ao direito à imagem, importante destacar sua natureza jurídica de direito personalíssimo que se refere ao reconhecimento da imagem do indivíduo e dele decorre o direito à identidade. Segundo Luiz Alberto David Araujo e Vidal Serrano Nunes Jr., esse direito fundamental possui duas facetas e deve ser observado como:

\begin{abstract}
De um lado, deve ser entendido como o direito relativo à reprodução gráfica (retrato, desenho, fotografia, filmagem etc.) da figura humana. De outro, porém, a imagem assume a característica do conjunto de atributos cultivados pelo indivíduo e reconhecidos pelo conjunto social. Chamemos a primeira de imagem-retrato e a segunda de imagem atributo ${ }^{45}$.
\end{abstract}

Em decorrência disso, somente o titular do direito em tela pode dispor do uso da sua imagem, com a devida autorização, para fins econômicos ou não. Cabe mencionar que da mesma forma como previsto aos direitos à honra, intimidade e vida privada, ao direito à imagem, também, é inviolável e está configurado no artigo $5^{\circ}$ da Constituição Federal, incisos V e X.

Portanto, atualmente o perfil genético também perfaz a imagem de um ser humano e, portanto, os dados inerentes ao mesmo podem conduzir a condutas deliberadamente configuradoras de ilícitos civis e tipos penais aclamados pela legislação penal pátria.

Já no que se refere ao direito à liberdade, é importante observar que seu conceito sofreu transformações, uma vez que a evolução da sociedade e do modo de vida das pessoas implicou em adaptação da compreensão deste direito. A liberdade antiga era exercida através da participação ativa na vida social e decisões políticas, já a moderna implica na participação direta das pessoas nas coisas do Estado (o representante é escolhido pelo povo) e na forma de decidir e viver individualmente, cada pessoa, o seu espaço ${ }^{46}$.

Assim, a Constituição de 1988 , em seu artigo $5^{\circ}$ passou a prever a liberdade de locomoção (inciso XV), liberdade de manifestação de pensamento (inciso IV), liberdade religiosa (inciso VI), liberdade de reunião (inciso XVI), liberdade de associação (incisos XVII e XX), liberdade de ação profissional (inciso XIII) e liberdade de informação (inciso XIV). Somado a isso, no artigo 170, parágrafo único do mesmo diploma constitucional está prevista a liberdade econômica.

Dessa forma, verifica-se que é possível apresentar inúmeras definições para a palavra liberdade, entretanto, o entendimento de José Afonso da Silva sobre o tema se faz importante, pois engloba todas as hipóteses previstas no direito à liberdade ao determinar que liberdade "é a possibilidade de coordenação consciente dos meios necessários à realização da felicidade pessoal" 47 .

O uso constante e indiscriminado dos dados constantes no microchip pode constituir violação à ao direito à liberdade, posto que o direito à não vigilância também é categorizado como direito constitucional, inclusive tendo sua origem na expressão "righttobeletalone" cunhada por Samuel Warren e Louis Brandeis em 1890.

Além disso, vale novamente reforçar a ideia de que uma vez que os mencionados direitos fundamentais forem desrespeitados, haverá, consequentemente, a violação ao princípio da dignidade da pessoa humana (possui valor supremo na Constituição Federal):

Onde não houver respeito pela vida e pela integridade física e moral do ser humano, onde as condições mínimas para uma existência digna não forem asseguradas, onde não houver limitação do poder, enfim, onde a liberdade e autonomia, a igualdade (em direitos e dignidade) e os direitos fundamentais não forem reconhecidos e minimamente

\footnotetext{
${ }^{45}$ ARAUJO, Luiz Alberto David; NUNES JUNIOR, Vidal Serrano. Curso de Direito Constitucional. 12 ed. São Paulo: Saraiva, 2008. P. 155.

${ }^{46}$ FACHIN, Zulmar. Curso de Direito Constitucional. 5. ed. Rio de Janeiro: Forense, 2012

${ }^{47}$ SILVA, José Afonso da. Curso de direito constitucional positivo. 20. ed. São Paulo: Malheiros, 2002. p. 232
}

Revista de Direito Brasileira | Florianópolis, SC | v. 23 | n. 9 | p. 28-49 |Mai./Ago. 2019 
assegurados, não haverá espaço para a dignidade da pessoa humana e esta (a pessoa), por sua vez, poderá não passar de mero objetivo de arbítrio e injustiça ${ }^{48}$.

Portanto, neste contexto do microchip humano o "Grande Irmão" (Big Brother) de George Orwell está sedimentando-se no mundo do século XXI.

\subsubsection{A utilização do microchip nas relações de emprego como casuística}

A utilização do microchip humano pode substituir os cartões de identificação para acesso às empresas e prédios comerciais, acesso a computadores, bem como a coleta da digital nos famosos pontos eletrônicos. Basta a aproximação da mão no leitor ou scanner e pronto, o biohackerjá tem seu acesso liberado no local e, também, é possível manter registrado o seu horário de entrada e saída.

Diante dessa comodidade e facilidade, muitas empresas ao redor do mundo, já colocaram a disposição de seus empregados a possibilidade de implantação de chips. O primeiro país a adotar essa ideia foi a Suécia, onde existem empresas que já "usam a tecnologia para o acesso de seus funcionários no dia a dia. Com o chip instalado na mão, basta acenar próximo ao sensor para registrar a entrada ou saída". ${ }^{49}$ Nos Estados Unidos, a empresa de tecnologia "Three Square Market" anunciou que implantaria esses chips e um mês após o anúncio, 61 dos 80 empregados já estavam como o microchip em seus corpos. ${ }^{50}$

De forma mais lenta, no Brasil, testes individuais já foram feitos, mas não há políticas empresariais para implantação de microchip ${ }^{51}$, entretanto, a empresa fabricante do microchip, Three Square Market, acredita que o país é o próximo a voltar suas atenções para esse mercado, uma vez que algumas empresas brasileiras já demonstraram interesse em adotar essa medida para seus empregados. ${ }^{52}$

Assim, importante frisar que a utilização desse dispositivo tecnológico nas relações de emprego será admitida somente nos casos em que não represente uma imposição por parte do empregador, haja vista a regra básica existente nas mencionadas relações, o contrato de trabalho não pode ser alterado unilateralmente pelo empregador. ${ }^{53}$

O artigo 468 da CLT é cristalino ao determinar que as alterações no contrato de trabalho individuais somente serão consideradas lícitas se houver mútuo consentimento e se a alteração não resultar em prejuízo ao empregado, sob pena de serem consideradas nulas.

Relevante frisar, portanto, que no Direito do Trabalho, tendo em vista as especificidades da relação de emprego, não basta a higidez na manifestação de vontade do empregado quanto à alteração do pactuado (consentimento). Também se exige que a modificação da

\footnotetext{
${ }^{48}$ SARLET, Ingo Wolfgang. Dignidade da Pessoa Humana e Direitos Fundamentais na Constituição Federal de 1988. Nona Ed. Porto Alegre: Livraria do Advogado, 2011. p.71.

${ }^{49}$ ÉPOCA NEGOCIOS. Na Suécia, 3 mil pessoas já usam microchips sob a pele -e não temem as consequências. Disponível em <https://epocanegocios.globo.com/Tecnologia/noticia/2018/05/na-suecia-3-mil-pessoas-ja-usammicrochips-sob-pele-e-nao-temem-consequencias.html> . Acesso em: 29 mai. 2018.

${ }^{50}$ SENRA, Ricardo. Brasil será nosso próximo mercado, diz CEO que implantou chips no corpo de funcionários nos EUA. Disponível em <https://g1.globo.com/tecnologia/noticia/brasil-sera-nosso-proximo-mercado-diz-ceo-queimplantou-chips-no-corpo-de-funcionarios-nos-eua.ghtml> Acesso em: 29 mai.2018.

${ }^{51}$ ÉPOCA NEGOCIOS. Na Suécia, 3 mil pessoas já usam microchips sob a pele -e não temem as consequências. Disponível em <https://epocanegocios.globo.com/Tecnologia/noticia/2018/05/na-suecia-3-mil-pessoas-ja-usammicrochips-sob-pele-e-nao-temem-consequencias.html.> Acesso em: 29 mai. 2018.

${ }^{52}$ SOUZA, Elson de. Implante de chips em funcionários: tecnologia polêmica está a caminho do Brasil . Disponível em <https://olhardigital.com.br/noticia/implante-de-chips-em-funcionarios-tecnologia-polemica-esta-a-caminho-dobrasil/71174>. Acesso em: 28 fev. 2018.

${ }^{53}$ MARTINS, Sérgio Pinto. Direito do Trabalho. 32 ed. São Paulo: Saraiva, 2016. p.500.
}

Revista de Direito Brasileira | Florianópolis, SC | v. 23 | n. 9 | p.28-49 |Mai./Ago. 2019 
condição de trabalho, para ser válida, não acarrete prejuízo (direto ou indireto) ao trabalhador. ${ }^{54}$

Portanto, a realização do implante não pode ser um requisito para a continuidade do contrato de trabalho, principalmente porque este dispositivo permite a violação do direito à intimidade e privacidade e, consequentemente, o princípio da dignidade da pessoa humana, previsto na Constituição Federal como um dos fundamentos de todo o sistema constitucional. Isso significa que, as empresas que tiverem interesse, poderão colocar a disposição de seus empregados a possibilidade de implantação do microchip em suas mãos, sem qualquer custo para o trabalhador, uma vez que serão usados como ferramentas que favorecerão o empregador.

Diante desse cenário, é possível afirmar que as empresas brasileiras poderão aderir à essa conduta de microchip humano para controle de acesso às suas instalações, controle de jornada, bem como acesso à computadores ou outras ferramentas de trabalho, desde que respeitem a disposição legal existente e transmita a responsabilidade da decisão (realização do procedimento ou não) inteiramente ao empregado, estabelecendo que para os trabalhadores que optarem por não implantar o chip, o acesso e controles de jornada continuarão sendo os mesmos realizados até então, sem qualquer discriminação no tratamento.

\section{ALGUNS ASPECTOS SOBRE A RESPONSABILIZAÇÃO EM RELAÇÃO AOS DADOS PESSOAIS DOS MICROCHIPS HUMANOS}

A responsabilização pela violação ao direito à intimidade e privacidade, bem como honra, liberdade e imagem, decorrentes das novas tecnologias ainda é assunto que está em fase de adaptações, haja vista a atualidade do tema e a rapidez das transformações tecnológicas que permitem mudanças na forma de vida das pessoas.

Quando observado o microchip humano e as possibilidades e facilidades que esse proporciona, verifica-se a necessidade de proteção rigorosa do bem em questão, por parte do fornecedor do microchip, uma vez que armazenam dados pessoais dos biohackerse de uma previsão para responsabilizar qualquer dano causado.

A Constituição Federal determina que uma vez violado o direito à intimidade, privacidade, honra e imagem, deverá ocorrer a indenização pelo dano causado (artigo $5^{\circ}$ ).

O Código Civil também trata do tema e prevê que comete ilícito aquele que por ação ou omissão voluntária, negligência ou imprudência, violar direito e causar dano a outrem (artigo 186) e, justamente por praticar esse ato, tem a obrigação de reparar o prejuízo causado (artigo 927). O artigo 12 do mesmo diploma legal prevê, ainda, a possibilidade de pleito por perdas e danos em razão de ameaça ou lesão ao direito da personalidade. Esse entendimento é aplicado aos problemas decorrentes da internet e dos avanços tecnológicos, inclusive para as hipóteses de violação que possam vir a acontecer em razão do uso do microchip humano.

Tanto o é que a Lei Geral de Proteção de Dados prevê, como fundamento, em seu artigo $2^{\circ}$, ainviolabilidade da intimidade, da honra e da imagem, bem como insere o art. 31 do citado diploma que estabelece que os órgãos públicos estão sujeitos às medidas administrativas específicas e que por conta disso, cabe a autoridade nacional ${ }^{55}$ garantir que medidas cabíveis e proporcionais sejam adotadas quando da violação do tratamento de dados pessoais Ainda, o legislador insere em seu artigo 42 a obrigação de reparação dos danos (sejam morais ou materiais), pelos agentes de tratamento, sempre que houver dano ou prejuízo ao titular dos dados.

\footnotetext{
${ }^{54}$ GARCIA, Gustavo Filipe Barbosa. Curso de Direito do Trabalho. 11 ed. Rio de Janeiro: Forense, 2017. p. 590.

${ }^{55}$ DIARO OFICIAL DA UNIÃO de 28/12/2018. A autoridade nacional de proteção de dados foi criada através da Medida Provisória n. 869 de 27 de dezembro de 2018, alterando a Lei 13.709 de 14 de agosto de 2018.
} 
Segundo Mário Cots e Ricardo Oliveira, o artigo 42 determina que o controlador ou operador devem responder pelos danos que causarem de forma individual ou solidária:

cada um é responsável pelos atos que praticou e pelos danos que causou, não havendo, por via de regra, a aplicação de responsabilidade civil solidária ou subsidiária entre eles.

...

Contudo, a LGPD criou duas hipóteses de responsabilidade solidária nas quais o operador responderá juntamente com o controlador pelos danos causados, prevista no $\S$ $1^{\circ}$, quais sejam: (i) quando o operador violar a LGPD; e (ii) quando operador não seguir as instruções de tratamento estabelecidas pelo controlador. ${ }^{56}$

Somado a isso, deve-se destacar que a relação entre o biohacker e o fabricante do microchip (responsável pelo armazenamento dos dados pessoais) é de consumo e, portanto, devem ser aplicadas as regras previstas no Código de Defesa do Consumidor, em especial as contidas nos artigos $6^{\circ}$ e 14 , que estabelecem o direito, do consumidor, de ser reparado por qualquer dano patrimonial e moral, bem como a responsabilidade objetiva do fornecedor, pelos prejuízos ocorridos.

Dessa forma, os próprios autores da violação (responsáveis diretos) ou ainda, os prestadores de serviços (responsáveis indiretos) serão responsabilizados por violação aos direitos constitucionais, valendo destacar que os responsáveis indiretos nem sempre responderão pelo dano causado, pois a responsabilidade desses é subjetiva, uma vez que "não se pode exigir dele o impossível, que é monitorar, a todo tempo, todos os incontáveis dados inseridos em seu servidor pelos usuários." $" 57$

É possível verificar, então, a imensa responsabilidade e comprometimento que devem ter as empresas responsáveis pelos bancos de dados, onde ficam armazenados todos os dados pessoais constantes em cada microchip, uma vez que qualquer vazamento de dados acarretará em violação à direito fundamental.

\section{CONCLUSÃO}

O avanço tecnológico continua influenciando de forma significativa o modo de organização da sociedade e dentre essas mudanças, a utilização do microchip humano merece destaque especial. A ideia de implantação subcutânea de um chip nos seres humanos para armazenar dados pessoais, permitir acesso à locais e veículos, bem como armazenar fichas médicas e dados médicos revoluciona totalmente o modus vivendi habitual das pessoas.

A partir deste contexto, inúmeros reflexos positivos e negativos passam a surgir, principalmente, no que se refere ao mundo jurídico. A utilização do microchip humano sem a devida observância à Declaração Universal dos Direitos Humanos e, no cenário brasileiro, sem respeitar as determinações da Constituição Federal, Código Civil e Lei Geral de Proteção de Dados caracterizará grave violação à direitos constitucionais, notadamente os direitos à intimidade, à privacidade, à honra, à imagem e ao próprio Princípio da Dignidade da pessoa humana.

Os dados armazenados no microchip humano são dados pessoais e, portanto, devem ser rigorosamente armazenados nos bancos de dados e somente podem ser fornecidos para terceiros com a devida autorização e por vontade do proprietário de cada dado. Por tal razão, na sociedade informacional, onde o bem mais valioso é a informação, já foram travadas inúmeras discussões

\footnotetext{
${ }^{56}$ COTS, Márcio; OLIVEIRA, Ricardo. Lei geral de proteção de dados pessoais comentada. São Paulo: Thomson Reuters Brasil, 2018. p. 225.

${ }^{57}$ NASCIMENTO, Bárbara Luiza Coutinho do. Liberdade de expressão, honra e privacidade na internet - A evolução de um conflito entre direitos fundamentais. Ebook ISBN 9781456360290. 1 ed. Rio de Janeiro, 2010. p. 96.

Revista de Direito Brasileira | Florianópolis, SC | v. 23 | n. 9 | p.28-49 |Mai./Ago. 2019
} 
sobre a forma de proteção dos dados, bem como maneiras de indenização por qualquer violação ocorrida, tendo como resultado, a aprovação de legislações específicas regulamentando essa prática no país e no mundo, entretanto, muito ainda há para se discutir sobre o assunto.

Oportuno destacar que no Brasil, essa conduta de implantação de microchip humano ainda não avançou na prática, eis que o uso do mencionado dispositivo, entretanto, isso deve mudar em breve já que a sociedade do século XXI é informacional, o que se quer dizer que é global e em rede transnacional. Por esse motivo, a necessidade do estudo acurado sobre a temática que verte consequências nas searas jurídica, política, econômica e social-cultural.

Vale destacar, conforme demonstrado, que se os dados pessoais, constantes no microchip humano, forem comercializados ou disponibilizados sem a devida autorização do seu proprietário, acarretará em grave desobediência ao texto constitucional e violação ao princípio da dignidade da Pessoa Humana, bem como aplicação de uma das sanções administrativas existentes na LGPD, conforme disposto no artigo 52 da referida lei. Citadas sanções administrativas têm como objetivo fazer com que as entidades responsáveis pelo tratamento de dados pessoais fiquem atentas à garantia da segurança referente às informações que estão utilizando, buscando assim a tutela preventiva do tratamento de dados pessoais.

Portanto, o presente trabalho, objetiva apresentar os principais pontos deste novo mundo nascente no século XXI e demonstrar que sua aplicação e utilização devem ser feitam segundo os ditames constitucionais balizados pelos direitos, garantias e princípios neles colimados.

\section{REFERÊNCIAS}

ALEXY, Robert. Derechosfundamentales, ponderación y racionalidad. In: FÉRNANDEZ SEGADO, F. (ed). The Spanish Costitution in theEuropeanConstitutionalContext/La ConstituciónEspañolaenel Contexto Constitucional Europeo. Madrid: Dykinson, 2013.

ALONSO, Felix Ruiz. Direito à privacidade. Porto Alegre: Síntese, 2004.

ANDRADE, Frederico PupoCarrijo de. Análise comparativa do tratamento de dados pessoais à luz do direito de personalidade. Anais do I Congresso Internacional: "Os desafios do direito face às novas tecnologias" da Faculdade de Direito de Ribeirão Preto. Disponível em http://www.direitorp.usp.br/wpcontent/uploads/2014/11/FredericoAndradeAnalisecomparativa.pdf .

ARAUJO, Luiz Alberto David; NUNES JUNIOR, Vidal Serrano. Curso de DireitoConstitucional. 12 ed. São Paulo: Saraiva, 2008.

CASTELLS, Manuel. A Era da informação: economia, sociedade e cultura. Volume 1. Asociedade em Rede, 10. ed., São Paulo: Paz e Terra, 2007.

COMISSÃO EUROPEIA. Reforma em matéria de proteção de dados na UE: proteção de dados reforçada para os cidadãos europeus. Disponível em https://ec.europa.eu/commission/sites/beta-political/files/data-protection-factsheetcitizens_pt_0.pdf.

COMISSÃO EUROPEIA. Reforma em matéria de proteção de dados na UE:regras melhores para as empresas europeias. Disponível em: https://ec.europa.eu/commission/sites/betapolitical/files/data-protection-factsheet-business_pt.pdf. 
COTS, Márcio; OLIVEIRA, Ricardo. Lei geral de proteção de dados pessoais comentada. São Paulo: Thomson Reuters Brasil, 2018.

DISCOVERY BRASIL. Marcos da Tecnologia - Microchip. Disponível em: http://www.oarquivo.com.br/variedades/ciencia-e-tecnologia/2507-marcos-da-tecnologiamicrochip.html.

ÉPOCA NEGÓCIOS. Na Suécia, 3 mil pessoas já usam microchips sob a pele -e não temem as consequências. Disponível em https:/epocanegocios.globo.com/Tecnologia/noticia/2018/05/na-suecia-3-mil-pessoas-ja-usammicrochips-sob-pele-e-nao-temem-consequencias.html.

FACHIN, Zulmar. Curso de Direito Constitucional. 5. ed. Rio de Janeiro: Forense, 2012.

FULLER, Greice Patricia. A responsabilidade social e ambiental das entidades financeiras em face do Direito Ambiental como direito humano e da sociedade da informação. Revista daFaculdade de Direito Universidade Federal de Minas Gerais, n. 71, jul/dez.2017

FULLER, Greice Patricia. O meio ambiente hospitalar em face da Dignidade da Pessoa Humana no Direito Ambiental Brasileiro. Revista Brasileira de Direito Ambiental, abr/jun 2011.

GARCÍA DE ENTERRÍA, Eduardo. La Constitución como norma y el Tribunal Constitucional.Navarra: Thomson-Civitas, 2006

GARCIA, Gustavo Filipe Barbosa. Curso de Direito do Trabalho. 11 ed. Rio de Janeiro: Forense, 2017.

GARZÓN VALDÉS, Ernesto. Tolerancia, dignidad y democracia. Universidad Inca Garcilaso de la Vega. Lima: Fondo Editorial, 2006.

GÓMEZ ARBOLEYA, E. Sobre la noción de persona. Revista de Estudios Políticos, num. 47. Madrid: Instituto de EstudiosPoliticos, 1949.

HONORATO, Renata; TOZETTO, Claudia. Biochip, você ainda vai usar um. Disponível em https://veja.abril.com.br/tecnologia/biochip-voce-ainda-vai-usar-um/. Acesso em: 20 jun. 2018.

HOUAISS, Antonio e VILLAR, Mauro de Salles. Dicionário Houaiss da línguaportuguesa. Rio de Janeiro: Objetiva, 2001.

LEGAZ Y LACAMBRA, Luis. La noción jurídica de la persona y los derechos del hombre. In: Revista de Estudios Políticos, XI, Madrid: Instituto de Estudios Políticos, 1955.

MARINONI, Luis Guilherme; MITIDIERO, Daniel; SARLET, Ingo Wolfgang. Curso deDireito Constitucional.São Paulo: Revista dos Tribunais, 2014.

MARTINS, Sérgio Pinto. Direito do Trabalho. 32 ed. São Paulo: Saraiva, 2016.

MATTOS, Alessandro Nicoli de. Telemetria e Conceitos relacionados - uma visão geral dos sistemas de telemetria com ênfase em aplicações aeroespaciais. Trabalho disponibilizado como emailware. São José do Campo/SP: 2004. 
MORENO CORREA, Sandra; MORENO GOMEZ, Freddy y MEDINA CARDENAS, Sebastián. Reacción a cuerpo extraño por implantación de un microchip. Revista

CubanaInvestBioméd [online]. 2015, vol.34, n.1, p. 80-92.

NASCIMENTO, Bárbara Luiza Coutinho do. Liberdade de expressão, honra e privacidade na internet - A evolução de um conflito entre direitos fundamentais. Ebook ISBN 9781456360290. 1 ed. Rio de Janeiro, 2010.

NERY, Nelson. Constituição Federal anotada e explicada. 5. ed. Rio de Janeiro: Forense, 2012.

PECES-BARBA, Gregorio. La dignidad de la persona desde la filosofía del derecho. Cuadernos Bartolomé de las Casas. Madrid: Dykinson, 2003.

PEREZ LUÑO, Antonio Enrique. Los derechos fundamentales. Madrid: Tecnos, 1998.

PINHEIRO, Patrícia Peck. Proteção de dados pessoais: comentários à Lei n.13.70/2018, Saraiva: São Paulo, 2018.

RECASENS SICHES, Luis. Vida humana, sociedade y Derecho, Disponível em http://www.biblioteca.org.ar/libros/89607.pdf. Acesso em: 05 ago.2017.

REDE DE DEFESA E PROTEÇÃO ANIMAL DA CIDADE DE CURITIBA. Disponível em http://www.protecaoanimal.curitiba.pr.gov.br/Conteudo/Microchip.aspx. Acesso em: 15 jan. 2018.

REINALDO FILHO. Demócrito. A implantação de chips em seres humanos para uso médico e os riscos à privacidade. Disponível em https://www.boletimjuridico.com.br/doutrina/artigo/1450/a-implantacao-chips-seres-humanosuso-medico-os-riscos-privacidade.

RODOTÁ, Stefano. A vida na sociedade da Vigilância - a privacidade hoje. Rio de Janeiro: Renovar, 2008.

SARLET, Ingo Wolfgang. Dignidade da Pessoa Humana e Direitos Fundamentais na Constituição Federal de 1988. Nona Ed. Porto Alegre: Livraria do Advogado, 2011.

SARLET, Ingo Wolfgang.A eficácia dos direitos fundamentais. Porto Alegre: Livraria do Advogado, 1998.

SCORZELLI, Patrícia. A Comunidade Cibernética e o Direito. Rio de Janeiro: Lumen Juris, 1997.

SENRA, Ricardo. Brasil será nosso próximo mercado, diz CEO que implantou chips no corpo de funcionários nos EUA. Disponível em https://g1.globo.com/tecnologia/noticia/brasilsera-nosso-proximo-mercado-diz-ceo-que-implantou-chips-no-corpo-de-funcionarios-noseua.ghtml. 
SILVA, José Afonso da. Curso de Direito Constitucional Positivo.9. ed. São Paulo: Malheiros, 1993.

SILVEIRA, Sergio Amadeu da. Tudo sobre tod@s: redes digitais, privacidade e venda de dados pessoais.São Paulo: Edições Sesc São Paulo, 2017.

SMITH, Charles. Human Microchip Implantation. Journal of Technology Management \&Innovation, Santiago, v.3, n.3, p.151-160, 2008. Disponível em:

https://scielo.conicyt.cl/scielo.php?script=sci_arttext\&pid=S0718-

27242008000100015\&lng=es\&nrm=iso.

SOUZA, Elson de. Implante de chips em funcionários: tecnologia polêmica está a caminho do Brasil. Disponível em https://olhardigital.com.br/noticia/implante-de-chips-em-funcionariostecnologia-polemica-esta-a-caminho-do-brasil/71174.

THE ECONOMIST. The world's most valuable resource is no longer oil, but data. Disponível em https://www.economist.com/leaders/2017/05/06/the-worlds-most-valuable-resource-is-nolonger-oil-but-data.

WIKIPEDIA. Disponível em https://pt.wikipedia.org/wiki/Microchip. 